\title{
The Computational Study on (E)-3-(2-Chlorostyryl)-5,5-Dimethylcyclohex-2-Enone
}

\author{
S. ERYILMAZ ${ }^{a, *}$, M. GÜL ${ }^{b}, Z$ Z. KOZAK ${ }^{c}$ AND E. İNKAYA ${ }^{d}$ \\ ${ }^{a}$ Amasya University, Faculty of Arts and Sciences, Physics Department, Amasya, Turkey \\ ${ }^{b}$ Amasya University, Faculty of Arts and Sciences, Chemistry Department, Amasya, Turkey \\ ${ }^{c}$ Amasya University, Institute of Science, Chemistry Department, Amasya, Turkey \\ ${ }^{d}$ Amasya University, Central Research Laboratory, Amasya, Turkey
}

\begin{abstract}
A new isophorone derivative, (E)-3-(2-chlorostyryl)-5,5-dimethylcyclohex-2-enone, was synthesized by aldol reactions and characterized by single crystal diffraction method to determine the molecular structure. The computational analysis based on density functional theory with Becke's three-parameter hybrid functional was carried out using Lee, Yang and Parr correlation functional (B3LYP)/6-311++G(d,p), to investigate the structural parameters, the values of dipole moment, the total polarizability, the first-order hyperpolarizability for the non-linear optical behaviour and the thermodynamic parameters at different temperatures of the compound.
\end{abstract}

DOI: 10.12693/APhysPolA.132.738

PACS/topics: 31.15.E, 31.15.es

\section{Introduction}

The aldol reaction is the most important carboncarbon bond-forming reaction in organic synthesis. The important building fragments of biological active compounds, biomaterials, polymers etc. are synthesized via aldol reaction [1]. Reaction of isophorone, which is a colourless-to-yellowish liquid, with a characteristic peppermint-like smell, with aldehyde yielded $(E)-3$ (2-chlorostyryl)-5,5-dimethylcyclohex-2-enone under basic conditions. This aldol adduct has shown evident delocalization properties and therefore we have considered to examine its optical properties.

Density functional theory (DFT) is very popular among scientists working in computational chemistry and in other fields, because it gives satisfactory agreement with experimental data [2-4]. The quantum mechanical calculations, performed using DFT enable one to investigate the structural, spectroscopic, electronic and nonlinear optical (NLO) properties of molecules [5-7].

The organic compounds which have character of NLO have been used for optical modulation, optical switching, optical logic, optical memory for the emerging technologies in the area of telecommunications, transmission of optical signals, optical interconnection, sensing, frequency shifting, signal processing, laser and in the other applications of optoelectronics [8-10].

Organic molecules contain donor-acceptor groups, attached to an aromatic ring system, that increases charge transfer through $\pi$-electron delocalization [11]. The computational approaches allow to determine for NLO characteristics of the organic materials [12].

*corresponding author; e-mail: srpleryilmaz@gmail.com
We report the synthesis process and results of crystallographic analysis of the (E)-3-(2-chlorostyryl)-5,5dimethylcyclohex-2-enone and the values of dipole moment, total polarizability, first-order hyperpolarizability, to interpret NLO behaviour, changes of thermodynamic parameters at different temperatures, which were determined using the DFT/B3LYP/6-311++G(d,p) theory.

\section{Experimental details}

\subsection{Synthesis}

The (E)-3-(2-chlorostyryl)-5,5-dimethylcyclohex-2enone (3) was synthesized under nitrogen atmosphere from isophorone (1) and 2-chlorobenzaldhyde (2) via aldol reaction, under conditions of overnight stirring at room temperature (Fig. 1). Isophorone $(1.1 \mathrm{~mol})$ was added into the solution of 2-chlorobenzaldehyde $(1.2 \mathrm{~mol})$ in ethanol.
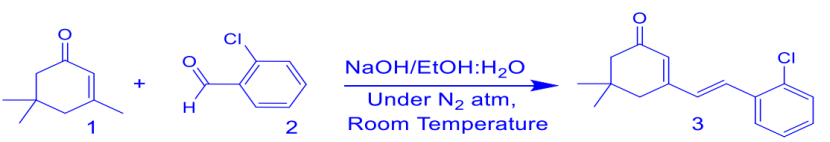

Fig. 1. Scheme of synthesis of (E)-3-(2-chlorostyryl)5,5-dimethylcyclohex-2-enone.

The $6 \mathrm{~N}$ sodium hydroxide solution was prepared in water:ethanol $(5: 5 \mathrm{ml})$ by dropwise addition over $30 \mathrm{mi}-$ nutes. Prior to column chromatography with ethylacetate:hexane (2:1), the compound was purified by extraction with ethyl acetate:brine system.

\subsection{Crystal analysis}

The single-crystal X-ray data were collected on a Bruker D8 QUEST diffractometer. The structure was solved by direct methods using SHELXS-97 [13], implemented in WinGX [14] program suit. Data collection: 
X-AREA, cell refinement: X-AREA, data reduction: $\mathrm{X}-\mathrm{RED} 32$ [15]. The investigated single crystal structure belongs to the monoclinic space group $P 21 / n$ with $Z=4$. The unit cell and lattice parameters are $a=5.7960(5) \AA$, $b=20.082(2) \AA, c=12.1977(12) \AA$ and $V=1400.0(2) \AA$ (CCDC Number:1505275). The compound contains 2chlorophenly and cyclohexenone groups. The ORTEP-3 view of the $(E)-3$-(2-chlorostyryl)-5,5-dimethylcyclohex2 -enone is shown in Fig. 2.

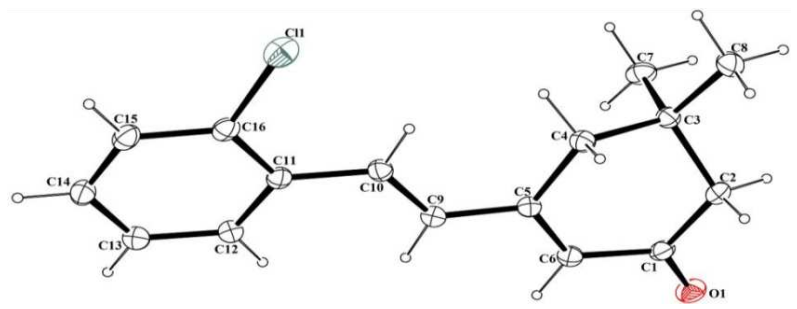

Fig. 2. An ORTEP-3 view of the chlorostyryl)-5,5-dimethylcyclohex-2-enone.

(E)-3-(2-

\section{Computational details}

All computational analyses were realized using Gaussian 09W [16] electronic structure calculation program and Gauss-View 5.0 interface program [17]. The optimization of the (E)-3-(2-chlorostyryl)-5,5dimethylcyclohex-2-enone was carried out using crystallographic data and the other theoretical studies were carried out based on this structure, using DFT/B3LYP/6$311++\mathrm{G}(\mathrm{d}, \mathrm{p})$ theory.

\section{Results and discussion}

\subsection{Optimized structure}

The optimized structure parameters, such as bond lengths and bond angles were compared with the obtained crystallographic data. C1-O1, C9-C10 bond lengths are $1.221(5), 1.332(5) \AA$, according to experimental results and 1.221, $1.349 \AA$, according to calculations. These values are in agreement with typical carbon-oxygen double bond lengths (of about $1.23 \AA$ ) and carbon-carbon double bond lengths (of about $1.33 \AA$ ). C9-C10-C11, O1-C1-C6 bond angles are $125.8(4)^{\circ}, 120.9(4)^{\circ}$, respectively, according to X-ray analysis data and $125.6^{\circ}, 121.4^{\circ}$, according to DFT/B3LYP/6-311++G(d,p) calculations. Similarly, when more parameters were compared, it was determined that the experimental and theoretical values are compatible with each other. The values of some selected experimental and theoretical parameters are shown in Table I.

TABLE I

Some selected experimental and theoretical geometrical parameters of the (E)-3-(2-chlorostyryl)5,5-dimethylcyclohex-2-enone.

\begin{tabular}{c|c|c|c|c|c}
\hline \hline $\begin{array}{c}\text { Bond } \\
\text { length }\end{array}$ & $\begin{array}{c}\text { Exp./Theo. } \\
{[\AA]}\end{array}$ & $\begin{array}{c}\text { Bond } \\
\text { angle }\end{array}$ & $\begin{array}{c}\text { Exp./Theo. } \\
{\left[{ }^{\circ}\right]}\end{array}$ & $\begin{array}{c}\text { Torsion } \\
\text { angle }\end{array}$ & $\begin{array}{c}\text { Exp./Theo. } \\
{\left[{ }^{\circ}\right]}\end{array}$ \\
\hline C1-O1 & $1.221(5) / 1.221$ & C9-C10-C11 & $125.8 / 125.6$ & O1-C1-C6-C5 & $-174.1(4) /-177.1$ \\
C16-Cl1 & $1.741(4) / 1.764$ & O1-C1-C6 & $120.9(4) / 121.4$ & O1-C1-C2-C3 & $147.6(4) / 149.4$ \\
C9-C10 & $1.332(5) / 1.349$ & O1-C1-C2 & $122.4 / 121.8$ & C6-C5-C9-C10 & $179.8(4) / 177.0$ \\
C5-C9 & $1.450(5) / 1.455$ & C10-C9-C5 & $126.1 / 125.8$ & C10-C11-C16-C15 & $-178.7(3) / 179.7$ \\
C10-C11 & $1.473(5) / 1.464$ & C11-C16-Cl1 & $120.4(3) / 120.6$ & C12-C11-C16-Cl1 & $-177.9(3) / 179.8$
\end{tabular}

\subsection{NLO analysis}

In order to interpret the NLO character of the $(E)-3$ (2-chlorostyryl)-5,5-dimethylcyclohex-2-enone, the total dipole moment, $\mu_{\text {tot }}$, the total polarizability $\alpha_{\text {tot }}$, and the magnitude value of first-order hyperpolarizability can be calculated using the following equations [18, 19];

$$
\mu_{\mathrm{tot}}=\left(\mu_{x}^{2}+\mu_{y}^{2}+\mu_{z}^{2}\right)^{1 / 2},
$$

$$
\begin{aligned}
& \alpha_{\mathrm{tot}}=\left(\alpha_{x x}+\alpha_{y y}+\alpha_{z z}\right) / 3, \\
& \beta_{\mathrm{tot}}=\left[\left(\beta_{x x x}+\beta_{x y y}+\beta_{x z z}\right)^{2}+\left(\beta_{y y y}+\beta_{y z z}+\beta_{y x x}\right)^{2}\right. \\
& \left.\quad+\left(\beta_{z z z}+\beta_{z x x}+\beta_{z y y}\right)^{2}\right]^{1 / 2} .
\end{aligned}
$$

The results are shown in Tables II and III.

TABLE II

The dipole moment and polarizability values of (E)-3-(2-chlorostyryl)-5,5-dimethylcyclohex-2-enone.

\begin{tabular}{c|c|c|c|c|c|c|c}
\hline \hline$\mu_{x}$ & $\mu_{y}$ & $\mu_{z}$ & $\mu_{\text {tot }}(\mathrm{D})$ & $\alpha_{x x}$ & $\alpha_{y y}$ & $\alpha_{z z}$ & $\begin{array}{c}\alpha_{\text {tot }} \\
\left(\times 10^{-24} \mathrm{esu}\right)\end{array}$ \\
\hline 3.7561 & 1.6703 & 1.0607 & 4.2454 & 53.1511 & 31.6664 & 19.6564 & 34.8246
\end{tabular}


TABLE III

The first-order hyperpolarizability values of (E)-3-(2-chlorostyryl)-5,5-dimethylcyclohex-2-enone.

\begin{tabular}{c|c|c|c|c|c|c|c|c|c|c}
\hline \hline$\beta_{x x x}$ & $\beta_{x x y}$ & $\beta_{x y y}$ & $\beta_{y y y}$ & $\beta_{x x z}$ & $\beta_{x y z}$ & $\beta_{y y z}$ & $\beta_{x z z}$ & $\beta_{y z z}$ & $\beta_{z z z}$ & $\begin{array}{c}\beta_{\text {tot }} \\
\left(\times 10^{-33} \mathrm{esu}\right)\end{array}$ \\
\hline-17344.79 & -636.01 & 670.57 & -952.44 & -924.02 & 64.01 & 215.40 & 340.91 & 174.52 & 239.75 & 16401.10
\end{tabular}

These values are reported in atomic units (a.u.) in GAUSSIAN 09W output, but polarizability and firstorder hyperpolarizability units have been converted into esu (electrostatic units), ( $\alpha$ : 1 a.u. $=0.1482 \times 10^{-24} \mathrm{esu}$; $\beta: 1$ a.u. $\left.=8.6393 \times 10^{-33} \mathrm{esu}\right)[20]$.

\subsection{Thermodynamic properties}

The heat capacity, $C_{p, m}^{0}$, entropy, $S_{m}^{0}$ and enthalpy change, $\Delta H_{m}^{0}$ values were calculated for 1 atm. pressure, at different temperature values (from 100 to $600 \mathrm{~K}$ ) and the results are listed in Table IV. Additionally, for the $(E)$-3-(2-chlorostyryl)-5,5-dimethylcyclohex-2-enone compound, the correlation equations for thermodynamic properties as functions of temperature and corresponding correlation coefficients are given below in Eqs. 4-6. Correlation dependencies are also given in Fig. 3.

TABLE IV

Thermodynamic properties of (E)-3-(2-chlorostyryl)-5,5dimethylcyclohex-2-enone.

\begin{tabular}{c|c|c|c|c|c|c}
\hline \hline $\mathrm{T}[\mathrm{K}]$ & 100 & 200 & 298.15 & 400 & 500 & 600 \\
\hline $\begin{array}{c}C_{p, m}^{0} \\
{\left[\mathrm{cal} \mathrm{mol}^{-1} \mathrm{~K}^{-1}\right]}\end{array}$ & 26.137 & 45.991 & 65.940 & 85.697 & 102.937 & 116.992 \\
\hline $\begin{array}{c}S_{m}^{0} \\
{\left[\mathrm{cal} \mathrm{mol}^{-1} \mathrm{~K}^{-1}\right]}\end{array}$ & 87.098 & 112.723 & 135.575 & 158.377 & 179.888 & 200.297 \\
\hline $\begin{array}{c}\Delta H_{m}^{0} \\
{\left[\mathrm{kcal} \mathrm{mol}^{-1}\right]}\end{array}$ & 1.790 & 5.599 & 11.283 & 19.238 & 28.907 & 40.121
\end{tabular}

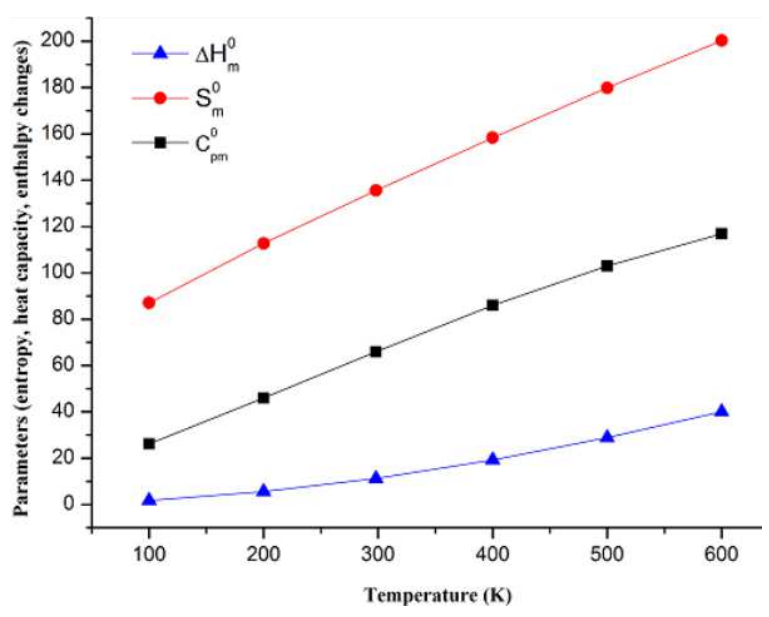

Fig. 3. Correlation graph for thermodynamic parameters of (E)-3-(2-chlorostyryl)-5,5-dimethylcyclohex2-enone.

$$
\begin{aligned}
& C_{p, m}^{0}(T)=2.465+0.238 T-7.651 \times 10^{-5} T^{2}, \\
& \quad\left(R^{2}=0.99913\right), \\
& S_{m}^{0}(T)=61.22+0.267 T-5.9213 \times 10^{-5} T^{2}, \\
& \quad\left(R^{2}=0.99994\right), \\
& \Delta H_{m}^{0}(T)=-0.353+0.0114 T+9.369 \times 10^{-5} T^{2}, \\
& \quad\left(R^{2}=0.99993\right)
\end{aligned}
$$

\section{Conclusions}

We have performed theoretical calculations using DFT/B3LYP/6-311++G(d,p) theory, to obtain knowledge about molecular geometry, NLO and thermodynamic properties of the (E)-3-(2-chlorostyryl)-5,5dimethylcyclohex-2-enone. The optimized structure parameters were found to be consistent with the results of crystallographic analysis. The dipole moment, polarizability, first-order hyperpolarizability values were calculated for the compound, and for the urea molecule, which were used as threshold values in the NLO analysis. The $\mu_{\text {tot }}, \alpha_{\text {tot }}$ and $\beta_{\text {tot }}$ values of the compound are 1.09, 6.89 and 21.61 times greater than the values of urea (values calculated for the urea molecule are $\mu_{\text {tot }}=3.8785 D$, $\left.\alpha_{\text {tot }}=5.0478 \times 10^{-24} \mathrm{esu}, \beta_{\text {tot }}=758.6813 \times 10^{-33} \mathrm{esu}\right)$. Based on these results, the compound can be considered worthy of study as a material for NLO applications, and suggested for the second-order non-linear optical research. Furthermore, in future studies, the NLO behaviour of this compound can be interpreted by comparing it with the para-nitro-aniline (pNA) molecule, which is another typical NLO material [21]. The values of thermodynamic parameters increase with rising temperature, due to the increase of molecular vibration motion intensity. In addition, these theoretical thermodynamic parameters may be useful for the synthesis of other isophorone derivatives.

\section{Acknowledgments}

We gratefully acknowledge the financial support of this work by the Amasya University Scientific Research Foundation (FMB-BAP-14-086). The authors acknowledge Central Research Laboratory, Amasya University and Scientific and Technological Research Application and Research Center, Sinop University, Turkey. 


\section{References}

[1] G. Casiraghi, F. Zanardi, G. Appendino, G. Rassu, Chem. Rev. 100, 1929 (2000).

[2] P. Hohenberg, W. Kohn, Phys. Rev. 136, B864 (1964).

[3] R.G. Parr, W. Yang, Density-functional Theory of Atoms and Molecules, Oxford Univ. Press, Oxford 1989.

[4] W. Koch, M.C. Holthausen, A Chemist's Guide to Density Functional Theory, John Wiley \& Sons, New York 2001.

[5] S. Xavier, S. Periandy, Spectrochim. Acta Part A 149, 216 (2015).

[6] H. Oturak, N.K. Kınaytürk, G. Şahin, Acta Phys. Pol. A 128, B-417 (2015).

[7] N.K. Kınaytürk, H. Oturak, Acta Phys. Pol. A $\mathbf{1 3 0}$ 276 (2016).

[8] M. Nakano, H. Fujita, M. Takahata, K. Yamaguchi, J. Am. Chem. Soc. 124, 9648 (2002).

[9] D. Sajan, D.H. Joe, V.S. Jayakumar, J. Zaleski, J. Molec. Struct. 785, 43 (2006).

[10] S. Eryılmaz, M. Gül, E. İnkaya, Ö. İdil, N. Ozdemir, J. Molec. Struct. 1122, 219 (2016).

[11] S.J. Lalama, A.F. Garito, Phys. Rev. A 20, 1179 (1979).

[12] P.N. Prasad, D.J. Williams, Introduction to Nonlinear Optical Effects in Molecules and Polymers, Wiley, New York 1991.

[13] G.M. Sheldrick, SHELXS-97, Program for the solution of crystal structures, University of Göttingen, 1997.

[14] L.J. Farrugia, J. Appl. Crystallogr. 32, 837 (1999).
[15] Stoe\&Cie, $X-R E D$, Ver. 1.04, Stoe\&Cie GmbH, Darmstadt, Germany 2002.

[16] M.J. Frisch, G.W. Trucks, H.B. Schlegel, G.E. Suzerain, M.A. Robb, J.R. Cheeseman Jr., J.A. Montgomery, T. Vreven, K.N. Kudin, J.C. Burant, J.M. Millam, S.S. Iyengar, J. Tomasi, V. Barone, B. Mennucci, M. Cossi, G. Scalmani, N. Rega, G.A. Petersson, H. Nakatsuji, M. Hada, M. Ehara, K. Toyota, R. Fukuda, J. Hasegawa, M. Ishida, T. Nakajima, Y. Honda, O. Kitao, H. Nakai, M. Klene, X. Li, J.E. Knox, H.P. Hratchian, J.B. Cross, V. Bakken, C. Adamo, J. Jaramillo, R. Gomperts, R.E. Stratmann, O. Yazyev, A.J. Austin, R. Cammi, C. Pomelli, J.W. Ochterski, P.Y. Ayala, K. Morokuma, G.A. Voth, P. Salvador, J.J. Dannenberg, V.G. Zakrzewski, S. Dapprich, A.D. Daniels, M.C. Strain, O. Farkas, D.K. Malick, A.D. Rabuck, K. Raghavachari, J.B. Foresman, J.V. Ortiz, Q. Cui, A.G. Baboul, S. Clifford, J. Cioslowski, B. Stefanov, G. Liu, A. Liashenko, P. Piskorz, I. Komaromi, R.L. Martin, D.J. Fox, T. Keith, M.A. AlLaham, C.Y. Peng, A. Nanayakkara, M. Challacombe, P.M.W. Gill, B. Johnson, W. Chen, M.W. Wong, C. Gonzalez, J.A. Pople, Gaussian 09, Gaussian Inc., Wallingford (CT) 2003.

[17] R. Dennington, T. Keith, J. Millam, GaussView, Ver. 5, Semichem Inc., Shawnee Mission, KS 2009.

[18] D.A. Klienman, Phys. Rev. 126, 1977 (1962).

[19] S. Ramalingam, M. Karabacak, S. Periandy, N. Puviarasan, D. Tanuja, Spectrochim. Acta Part A 96, 207 (2012).

[20] A. Esme, S.G. Sağdınç, Acta Phys. Pol. A 130, 1273 (2016).

[21] Ö. Tamer, A.A. Avcı, Y. Atalay, Acta Phys. Pol. A 126, 679 (2014). 